\title{
Análise dos Objetos de Aprendizagem Utilizados em Curso Técnico de Meio Ambiente a Distância
}

\section{The Analysis of the Learning Objects Used in a Distance-Based, Technical Program in Environmental Studies}

Márcia Gorett Ribeiro Grossi ${ }^{1}$

Débora Cristina Cordeiro Campos Leal ${ }^{1}$

${ }^{1}$ Centro Federal de Educação Tecnológica de Minas Gerais (CEFET-MG), Belo Horizonte, MG, Brasil. Autora correspondente: marciagrossi@cefetmg.br

Resumo: O objetivo deste artigo foi analisar os Objetos de Aprendizagem presentes no ambiente virtual de aprendizagem do Centro Federal de Educação Tecnológica de Minas Gerais, especificamente do curso técnico de Meio Ambiente ofertado a distância, com o intuito de verificar se atendem aos aspectos de avaliação de material didático em formato digital definidos por Sabota e Pereira. Trata-se de uma pesquisa qualitativa e descritiva. Quanto ao procedimento técnico, optouse pelo estudo de caso. Dentre os resultados, destaca-se que muitos dos recursos disponíveis no Ambiente Virtual de Aprendizagem do curso analisado não contemplam aspectos como interação e interatividade, engajamento, afetividade e flexibilização, aspectos esses necessários para o estabelecimento de uma efetiva prática pedagógica na Educação a distância (EaD). Por fim, demonstrou-se, nesta pesquisa, como os Objetos de Aprendizagem podem ser selecionados e analisados por professores no processo de ensino-aprendizagem.

Palavras-chave: Ensino a distância; Educação ambiental; Ambiente virtual de aprendizagem; Material didático digital; Objetos de aprendizagem.

Abstract: The aim of this article is to analyze the Learning Objects present in the virtual environment of Centro Federal de Educação Tecnológica de Minas Gerais, specifically in the technical program in Environmental Studies offered at distance, in order to verify if these Learning Objects meet the evaluation aspects of didactic material in digital format defined by Sabota and Pereira. This is a qualitative and descriptive research. Regarding the procedure, the case study was chosen. Among the results, it should be noted that many of the resources available in the virtual learning environment are not subject to a process of analysis such as interaction and interactivity, engagement, affectivity and flexibility, which are requirements for establishing good pedagogical practice in Distance Education. Finally, it was demonstrated, in this research, how an Learning Object can be selected and analyzed by teachers in the teaching and learning processes.

Keywords: Distance education; Enviromental education; Virtual learning environment; Digital didactic material; Learning objects.

Recebido em: 05/06/2019

Aprovado em: 30/10/2019 


\section{Introdução}

O avanço da tecnologia tem trazido mudanças para o dia a dia das pessoas, modificando os meios de produção, de comunicação, o convívio interpessoal, as relações de trabalho e a educação em todas as suas modalidades de ensino, como por exemplo, a Educação a Distância (EaD), a qual se adequa com mais facilidade às novas demandas, das quais decorrem das transformações tecnológicas (BELLONI, 2015). Neste sentido, o acesso e o uso das Tecnologias Digitais da Informação e Comunicação (TDIC) tem possibilitado a criação de novas mídias e recursos educacionais e também dos Ambientes Virtuais de Aprendizagem (AVA), local onde ocorre o processo de ensinar e de aprender a distância.

Dentro do universo das tecnologias digitais da informação e comunicação voltadas para a educação a distância, destacam-se os objetos de aprendizagem (OA) que oferecem diversas possibilidades pedagógicas digitais de ampliação do conhecimento no contexto educacional, cuja característica principal é a sua capacidade de reutilização. A este respeito, Wiley (2000) lembra que os Objetos de Aprendizagem, quando bem escolhidos, despertam a motivação e o interesse do aluno, fazendo com que esses objetos assumam um papel ativo e central no seu desenvolvimento educacional.

Outra característica dos Objetos de Aprendizagem é a necessidade de explicitação de seus objetivos pedagógicos. Assim, para que um recurso educacional seja considerado um objeto de aprendizagem, Silveira e Carneiro (2012) sustentam que eles devem ser autocontidos, ou seja, serem suficientes em relação a um determinado assunto, sem que seu usuário precise de outros materiais para entendê-lo. Considera-se também que, para além de um material digital, como uma apresentação de slides ou um vídeo, um Objeto de Aprendizagem precisa funcionar como um elemento facilitador do processo de ensino e aprendizagem, dando ao aluno subsídios para o seu desenvolvimento e autogerenciamento da sua aprendizagem.

Assim, os professores devem procurar por informações de recursos disponíveis, refletindo sobre a utilização de novas ferramentas digitais, não apenas fazendo uso da tecnologia por si só, mas aliando a uma metodologia adequada e atrelada ao objetivo de aprendizagem inicial estabelecido. Entre as possibilidades, evidencia o uso dos Objetos de Aprendizagem para cursos ofertados a distância, das quais exigem estratégias para escolha e análise, tendo como público os professores, designers instrucionais e demais profissionais envolvidos na mediação e elaboração de cursos ou disciplinas. Dentre estas estratégias de análise, destaca-se a de Sabota e Pereira (2017), que a presentam as constantes transformações das tecnologias aplicadas à educação, e demonstram uma metodologia para avaliar materiais didáticos em formato digital.

A partir de tal contexto surge a questão que inspirou esta pesquisa: os objetos de aprendizagem utilizados nos ambientes virtuais de aprendizagem de cursos ofertados a distância têm atendido aos aspectos de avaliação estabelecidos pelos autores Sabota e Pereira (2017)? Para responder a esta questão, escolheu-se uma instituição que ofertasse a educação a distância (EaD) para aplicar as estratégias para escolha e avaliação de um objeto de aprendizagem. Assim, foi escolhido o Centro Federal de Educação Tecnológica de Minas Gerais (CEFET-MG), que, dentre várias modalidades e níveis de ensino, oferta três cursos técnicos de nível médio na modalidade a distância: eletroeletrônica, informática para internet e meio ambiente, sendo o último, o foco deste estudo. 
Portanto, nesta perspectiva, o objetivo desta pesquisa foi analisar os Objetos de Aprendizagem presentes no ambiente virtual de aprendizagem do Centro Federal de Educação Tecnológica de Minas Gerais, especificamente do curso técnico de Meio ambiente ofertado a distância, com o intuito de verificar se esses objetos de aprendizagem atendem aos aspectos de avaliação de material didático em formato digital definidos por Sabota e Pereira (2017). Cabe ressaltar que este curso foi escolhido, entre os demais que o CEFETMG oferta a distância, pelo fato de ter apresentado mais objetos de aprendizagem em seu ambientes virtuais de aprendizagem, durante o desenvolvimento desta pesquisa.

\section{Referencial Teórico}

\section{Educação a distância e os ambientes virtuais de aprendizagem}

De acordo com Maia e Mattar (2007), a Educação a Distância é uma modalidade de educação na qual professores e alunos estão separados temporalmente e espacialmente, porém unidos pela tecnologia. $\mathrm{Na} \mathrm{EaD}$ os papéis de todos os envolvidos se modificam em relação à modalidade presencial na perspectiva tradicional de ensino. $O$ aluno se torna o centro do processo, deixa de ser um mero receptor para se tornar autônomo e responsável pela sua aprendizagem. O professor não é mais o ator principal, agora ele é o mediador do processo de ensino e aprendizagem, estimulando o debate, instigando a curiosidade e promovendo a interação entre todos os atores desse processo (OLIVEIRA, 2012).

Além desses entendimentos sobre a $\mathrm{EaD}$, existe a questão tecnológica, pois o desenvolvimento das tecnologias digitais tem impulsionado o crescimento desta modalidade de educação. Neste contexto, o uso das Tecnologias Digitais da Informação e Comunicação está estritamente relacionado à educação a distância, uma vez que essas tecnologias englobam uma série de softwares e ferramentas e representam todo o conjunto de recursos tecnológicos utilizados no processo de ensino e aprendizagem.

Neste sentido, Moore e Kearsley (2008) afirmam que a Educação a Distância já passou por diversas gerações, as quais são caracterizadas pelas tecnologias dominantes em cada época, sendo que a geração atual é conhecida como geração da web por utilizar recursos da internet ou world wide web (www) aliado a outras tecnologias. Este modelo impulsionou de forma significativa a EaD. Na geração atual usam-se mais recursos digitais, como hipertextos, áudios, vídeos, animações, visando o aprendizado em colaboração e uma alta interação entre alunos e professores de forma síncrona ou assíncrona.

Também, nesta geração atual, o local onde os cursos a distância são ofertados são os Ambientes Virtuais de Aprendizagem, espaços dos quais todo o processo de ensino e aprendizagem na modalidade a distância acontece e que estão relacionados às estratégias de aprendizagem mediadas pela tecnologia, com o objetivo de promover a construção do conhecimento e a interação dos alunos e professores (BISOL, 2010).

Ainda segundo o autor, o professor tem nos Ambientes Virtuais de Aprendizagem acesso aos registros publicados, como fóruns, mensagens e atividades. Ele pode ainda trocar experiências com outros colegas sobre a melhor forma de aplicar algum conteúdo com os alunos ou sobre qual melhor recurso digital utilizar, conforme o objetivo proposto. Nesta perspectiva, o professor não deve apenas coletar a informação, mas também saber selecionála e fazer uma análise crítica conforme as metodologias e objetivos propostos. 
Para Bisol (2010), o Ambiente Virtual de Aprendizagem oferece aos professores e aos alunos diversas vantagens, sendo a principal, favorecer a mediação da aprendizagem. Nesse ambiente de aprendizagem todos os registros, como participações e tarefas, ficam disponíveis, podendo ser acessados a qualquer momento, tanto pelo professor quanto pelo estudante, sendo necessário apenas que ele tenha um computador ou dispositivo móvel conectado à internet. Complementando, Maia e Garcia (2011) apontam a necessidade dos Ambientes Virtuais de Aprendizagem conter todas as ferramentas e recursos necessários para facilitar o acesso do aluno nas atividades propostas, para permitir uma visualização objetiva e clara das áreas que deve percorrer, além de conceder ao professor a atualização das informações referentes ao processo.

Contudo, cabe salientar que existem diversos tipos de Ambientes Virtuais de Aprendizagem, que podem ser utilizados tanto para educação a distância, como para suporte na modalidade presencial ou no ensino híbrido. Além das diferenças técnicas e de recursos, as plataformas de aprendizagem se diferem também quanto à forma de disponibilidade para o usuário, ou seja, podem ser pagos ou gratuitos. Portanto, fica a critério das instituições sua escolha, de forma que melhor atenda às suas necessidades. Na instituição da qual a pesquisa foi desenvolvida, o Centro Federal de Educação Tecnológica de Minas Gerais, utiliza-se o sistema modular Object-Oriented Dynamic Learning Environment (Moodle) por se tratar de um software livre. Além disso, o Moodle possui algumas características relevantes como confiabilidade, usabilidade e navegabilidade, o que faz com que muitas instituições optem por usá-lo.

Delgado (2009) explica que o Moodle possui duas formas de ser trabalhado: com os recursos, e com as atividades. Os recursos são ferramentas usadas para mostrar os conteúdos aos alunos, como por exemplo, livro, arquivo, página, pasta, Uniform Resource Locator (URL) ou links que direcionam para outras páginas. Já as atividades são ferramentas de comunicação ou avaliação como chat, fórum, glossário, tarefa, diário, enquetes, pesquisa de avaliação, wiki.

Entretanto, Grossi et al. (2018) alertam que para um Ambiente Virtual de Aprendizagem atuar de fato como um instrumento potencializador da aprendizagem na EaD, algumas características devem ser levadas em conta. Assim, foram definidos cinco parâmetros tecnológicos com o objetivo de proporcionar ao usuário um layout simples com interfaces amigáveis para permitir fácil navegação, bem como uma boa comunicação entre os agentes envolvidos (Quadro 1).

Quadro 1 - Parâmetros tecnológicos para os Ambientes Virtuais de Aprendizagem

\begin{tabular}{|l|l|}
\hline \multicolumn{1}{|c|}{ Parâmetros Tecnológicos } & \multicolumn{1}{c|}{ Características } \\
\hline Interoperabilidade & $\begin{array}{l}\text { Trata-se da capacidade de comunicação entre os sistemas. Em um Ambientes Virtuais de Aprendizagem } \\
\text { as funcionalidades precisam interoperar e colaborar, resultando na troca e reuso de funcionalidades. }\end{array}$ \\
\hline Usabilidade & $\begin{array}{l}\text { Refere-se a interfaces eficientes e agradáveis, de fácil utilização, rápida navegação, que atinja o objetivo } \\
\text { de uso, gere satisfação e que apresente poucos erros ao navegar pelo software. }\end{array}$ \\
\hline Desempenho & $\begin{array}{l}\text { Refere-se ao envolvimento e resultados obtidos pelos alunos através da utilização de um Ambientes } \\
\text { Virtuais de Aprendizagem (AVA). Diante disso, um AVA precisa possuir ferramentas que indiquem a } \\
\text { participação e envolvimento dos alunos, como quantidade de postagens em fóruns, relevância das } \\
\text { postagens, entrega de atividades, quantidade de acessos, dentre outros. }\end{array}$ \\
\hline $\begin{array}{l}\text { Ferramentas digitais para } \\
\text { aprendizagem }\end{array}$ & $\begin{array}{l}\text { Trata das ferramentas que auxiliam no processo de ensino e aprendizagem, ampliando as possibilidades } \\
\text { de acesso e construção do conhecimento, através de conteúdos dinâmicos e interativos, como por } \\
\text { exemplo, chats, videoconferências, games, fóruns, wikis, simulações, dentre outros. }\end{array}$ \\
\hline Ferramentas de administração & $\begin{array}{l}\text { Refere-se à estrutura de gerenciamento e administração do Ambiente Virtual de Aprendizagem, como } \\
\text { criação de novas turmas, inserção de participantes, instalação de plug-ins para personalização do } \\
\text { sistema, relatórios estatísticos, acesso a notas, histórico, elaboração de atividades, acompanhamento } \\
\text { da participação, dentre outros. }\end{array}$ \\
\hline
\end{tabular}

Fonte: adaptado de Grossi et al. (2018). 
Diante das características apresentadas no Quadro 1, observa-se que para a aprendizagem na educação a distância acontecer é necessário oferecer recursos e objetos que favoreçam o ensino por meio da interação entre os alunos e professores. Também, é importante garantir uma boa funcionalidade do Ambiente Virtual de Aprendizagem, propondo atividades e recursos que possam ser usados para a produção de conhecimento, sempre levando em consideração o material didático digital.

\section{Algumas considerações sobre o material didático digital para educação a distância}

Na Educação a Distância (EaD), o material didático digital tem um papel fundamental, sendo por muitos autores considerado a voz do professor, por ser um elemento mediador no processo, trazendo consigo a concepção pedagógica que irá nortear o processo de ensino e aprendizagem. Para Kenski (2013), o material didático possui importante função na $\mathrm{EaD}$, contribuindo para que o processo de ensino e aprendizagem se torne mais dinâmico, não apenas apresentando conteúdo, mas integrando habilidades, de forma a atender aos objetivos do professor e dos alunos. Para a autora, um bom material didático relaciona o conteúdo com conhecimentos prévios do aluno, fazendo um contexto histórico e social que o cerca.

Além disso, os professores precisam ter em mente a questão da interatividade, pois segundo Arrais (2013), nem tudo que é digital é interativo e nem tudo o que é interativo é digital. O fato de o usuário clicar várias vezes não torna o objeto interativo. Deste modo, o professor deve ter em mente estas questões para fazer uma escolha assertiva do material, que irá proporcionar ao aluno maior nível de interatividade, abrindo possibilidades de explorar diferentes recursos. Portanto, seja qual for o recurso utilizado na proposta pedagógica, todos devem buscar a interatividade, além de oferecer uma linguagem clara, dialógica e com exemplificações que favoreçam um constante diálogo entre aluno, professor e conhecimento, trazendo o conteúdo mais próximo da realidade do aluno, criando uma relação de sentido e significado.

Sobre esse aspecto, são diversos os tipos de recursos digitais que podem ser oferecidos na EaD. Sabota e Pereira (2017, p. 47) afirmam que, além do e-book, que seria o livro digital ou a apostila da disciplina, outros recursos são utilizados como "[...] ilustrações, charges, músicas, vídeos, jogos, apostilas, sequências didáticas, CD-ROM, e cursos de variados formatos digitais online acessíveis em sites da internet e, mais recentemente, aplicativos diversos que podem auxiliar o processo de desenvolvimento de aprendizagem autônoma".

Hodgins (2000) foi o primeiro autor a discutir os Objetos de Aprendizagem. Ele fez uma analogia com blocos do brinquedo Lego, associando a diversas possibilidades de seu uso e de reuso, conforme as necessidades dos alunos. Wiley (2000) questiona essa analogia, considerando a ideia muito simplista, pois seriam experiências educacionais dissociadas, sem ligação com avaliações para examinar se os objetivos de aprendizagem foram atingidos e define um Objeto de Aprendizagem como "[...] qualquer recurso digital que pode ser reusado para apoiar a aprendizagem" (WILEY, 2000, p. 7, tradução nossa).

Para o grupo de trabalho Learning Object Metadata (LOM) do Institute of Electrical and Electronics Engineers (IEEE), objeto de aprendizagem possui um conceito mais abrangente: "[...] qualquer entidade, digital ou não digital, que pode ser usada, reutilizada ou referenciada durante a aprendizagem apoiada por tecnologia" (INSTITUTE OF ELECTRICAL AND ELECTRONICS ENGINEERS, 2002, p. 6, tradução nossa). 
Complementando, Nikolopoulos et al. (2012) discutem as características necessárias que o objeto de aprendizagem deve possuir, que seriam a acessibilidade, a reusabilidade e a interoperabilidade. Para os autores, acessibilidade refere-se à facilidade de acesso e de uso do objeto; já reusabilidade refere-se ao fato de que o objeto pode ser reutilizável várias vezes, em diversas situações e disciplinas; e interoperabilidade diz respeito à possibilidade do Objeto de Aprendizagem operar em diferentes sistemas operacionais e ser acessado por qualquer tipo de navegador.

Portanto, para que seja eficaz no processo de ensino e aprendizagem, um Objeto de Aprendizagem (OA) deve carregar em sua estrutura um conjunto de características que propiciem ao aluno condições significativas de aprendizagem, sendo que a produção de um OA perpassa por diversos profissionais, dentre eles, pedagogos, professores, designers instrucionais, designers gráficos, programadores, ilustradores e revisores. Segundo Silveira e Carneiro (2012), os princípios para a construção dos objetos de aprendizagem buscam integrar a usabilidade do design e a usabilidade pedagógica.

\section{Critérios para análise e avaliação de materiais didáticos digitais segundo Sabota e Pereira}

Sabota e Pereira (2017) propõem três aspectos para a nalisar e avaliar materiais didáticos digitais de diversas áreas do conhecimento, dentre esses os Objetos de Aprendizagem: técnicos, teóricos e práticos.

Com relação aos aspectos técnicos, os autores consideram os elementos que são referentes às características operacionais do Ambiente Virtual de Aprendizagem. Tendo em vista que todos os recursos digitais são disponibilizados na plataforma, é importante no primeiro momento realizar uma análise do ambiente utilizado para verificar sua viabilidade de uso, levando em conta uma experiência bem sucedida por parte do usuário (SABOTA; PEREIRA, 2017).

Sobre a experiência de navegação no Ambiente Virtual de Aprendizagem, os autores apontam que existem questões de interface que podem frustrar o aluno em sua tentativa de aprender, como por exemplo, a dificuldade de compreender os comandos e localizar funções. Segundo os autores, "[...] a ferramenta, para atender à sua função facilitadora do acesso ao conhecimento [...] deve tornar-se uma ponte entre o usuário e o que ele deseja aprender/acessar" (SABOTA; PEREIRA, 2017, p. 51). Por conseguinte, tendo o Ambiente Virtual de Aprendizagem como suporte inicial dos objetos de aprendizagem, ele pode ser avaliado pelos aspectos apresentados no Quadro 2.

Percebe-se, portanto, que a intenção de Sabota e Pereira (2017) é facilitar o acesso e a navegação para proporcionar uma melhor experiência ao usuário e permitir o alcance dos objetivos de aprendizagem previamente estabelecidos. Por esta razão, foi incluída nos aspectos técnicos a questão de acessibilidade. 
Quadro 2 - Aspectos técnicos relacionados à avaliação do Ambiente Virtual de Aprendizagem

\begin{tabular}{|l|l|}
\hline \multicolumn{1}{|c|}{ Aspectos técnicos } & \multicolumn{1}{c|}{ Detalhamento } \\
\hline Design / Layout & $\begin{array}{l}\text { Exame da aparência do Ambiente Virtual de Aprendizagem, observando como ele é apresentado ao usuário. } \\
\text { Com isso saber se esse AVA pode ser considerado um espaço amigável, de fácil acesso ao usuário e, com } \\
\text { atividades autoexplicativas ou que apresentem tutoriais. Também neste item, verifica-se se o Ambiente } \\
\text { Virtual de Aprendizagem é atrativo, apresentando imagens, gráficos e tabelas que auxiliem na compreensão } \\
\text { do conteúdo e, não usado para confundir o usuário. }\end{array}$ \\
\hline Acessibilidade & $\begin{array}{l}\text { Este aspecto contempla questões referentes ao modo como o Ambiente Virtual de Aprendizagem facilita a } \\
\text { interação do usuário com o conteúdo proposto. São considerados aqui se é demandado cadastro de usuário, } \\
\text { se pode ser acessada a partir de diversos suportes, permite ou não a integração de mídias, faz seleção e/ou } \\
\text { restrições de participantes. }\end{array}$ \\
\hline Suporte & $\begin{array}{l}\text { Neste aspecto, avalia-se o cuidado para com o aluno e o professor no uso das ferramentas digitais do Ambiente } \\
\text { Virtual de Aprendizagem e, o auxílio oferecido durante o acesso. Nesse sentido, é importante descobrir se há: } \\
\text { a. seções de FAQ (perguntas mais comuns feitas por usuários); } \\
\text { b. tutoriais disponibilizados na ferramenta/aplicativo/AVA para auxiliar o entendimento de tarefas ou apli- } \\
\text { cativos menos conhecidos; } \\
\text { c. cuidado no uso da linguagem, ou seja, se evita o uso de termos técnicos relacionados à ferramenta; } \\
\text { d. previsão de acesso por pessoas com limitações/necessidades especiais (áudios ou possibilidade de au- } \\
\text { mento de fontes para deficientes visuais, por exemplo); } \\
\text { e. disponibilização de meios de contato (e-mail, telefone, chat) para solucionar dúvidas sem ônus para o usuário. }\end{array}$ \\
\hline
\end{tabular}

Fonte: Sabota e Pereira (2017, p. 52).

Com relação aos aspectos teóricos, os autores apresentam itens que buscam avaliar a disposição de elementos gráficos, isto é, se os materiais fornecem quesitos como interação e interatividade, se são tratados como processos de desenvolvimento cognitivo e, se trabalham a questão da mediação, da multimodalidade e da avaliação (Quadro 3).

Quadro 3 - Aspectos teóricos para avaliação de materiais didáticos em formato digital

\begin{tabular}{|l|l|}
\hline \multicolumn{1}{|c|}{ Aspectos teóricos } & \multicolumn{1}{c|}{ Detalhamento } \\
\hline $\begin{array}{l}\text { Concepção de ensino e de } \\
\text { aprendizagem }\end{array}$ & $\begin{array}{l}\text { Neste aspecto o que interessa saber é se o material foi desenvolvido com uma concepção didática, tratados } \\
\text { como processos de desenvolvimento pessoal e intelectual, e inseridos num contexto. }\end{array}$ \\
\hline Avaliação & $\begin{array}{l}\text { Atrelado às concepções de ensino e aprendizagem, está a presença ou não de elementos dos quais o aluno } \\
\text { possa ser avaliado ou avaliar seus pares. Nesse sentido, busca-se perceber como a avaliação é vista: como } \\
\text { parte de um planejamento de desenvolvimento do aprendiz, ou como instrumento aplicado para fornecer } \\
\text { um diagnóstico do estado atual do seu saber. }\end{array}$ \\
\hline Interação e Interatividade & $\begin{array}{l}\text { Neste aspecto o que interessa saber neste item se é prevista a interação entre pessoas, ou com o instrumento e } \\
\text { seu conteúdo (interatividade). Ainda é interessante saber se é possível fazer postagens endereçadas a colegas } \\
\text { e conexões de arquivos e conteúdos buscando ampliar o contato com outras pessoas por meio da ferramenta, } \\
\text { contemplando assim as questões de interação (entre indivíduos) e de interatividade (indivíduo-programa). }\end{array}$ \\
\hline Recursos & $\begin{array}{l}\text { Neste aspecto investiga-se se o conteúdo presente na TDIC, além de ilustrações, vídeos, elementos gráficos } \\
\text { e textos orais, escritos e imagéticos correlacionam-se com outros recursos e mídias. }\end{array}$ \\
\hline Multimodalidade & $\begin{array}{l}\text { Neste aspecto interessa saber se a ferramenta tecnológica oportuniza o desenvolvimento de letramentos } \\
\text { digitais por meio de tarefas que favoreçam a leitura não linear (com hiperlinks) e multimodal, ou seja, se há } \\
\text { tentativas de conectar diversos conteúdos e o incentivo à relação entre ideias provenientes de diferentes fontes. }\end{array}$ \\
\hline
\end{tabular}

Fonte: Sabota e Pereira (2017, p. 53).

A partir das informações do Quadro 3, percebe-se que os aspectos teóricos envolvem elementos no que concerne a formação do aluno e de seu desenvolvimento, tendo em vista a formação do cidadão do século XXI.

Com relação aos aspectos práticos, os autores levaram em conta como os alunos interagem com o conteúdo e entre si durante o uso do objeto, visando especialmente à autonomia do aluno e à afetividade (Quadro 4). 
Quadro 4 - Aspectos práticos para avaliação de materiais didáticos em formato digital

\begin{tabular}{|l|l|}
\hline \multicolumn{1}{|c|}{ Aspectos práticos } & \multicolumn{1}{c|}{ Detalhamento } \\
\hline Flexibilização & $\begin{array}{l}\text { O foco aqui é identificar se o usuário pode, por exemplo, navegar livremente pelo conteúdo ou atividades } \\
\text { e escolher a ordem de acesso, ou se a progressão sugerida pelo instrumento é rígida, não favorecendo o } \\
\text { desenvolvimento da autonomia do usuário. }\end{array}$ \\
\hline Engajamento & $\begin{array}{l}\text { Na busca de possibilitar ao aprendiz traçar seus próprios caminhos no processo de aprendizagem ao estudar } \\
\text { em um ambiente virtual de aprendizagem Ambiente Virtual de Aprendizagem (AVA) ou com o auxílio de } \\
\text { ferramentas digitais, é esperado que os instrumentos ajam como empoderadores neste processo, oferecendo } \\
\text { não apenas o acesso ao conteúdo, mas a oportunidade de desenvolvimento da consciência da aprendizagem. } \\
\text { O engajamento pode ser percebido pelo modo como o conteúdo ou as atividades convidam o usuário a } \\
\text { continuar usando a ferramenta e como preveem o acesso do usuário aos itens propostos. Algumas ferra- } \\
\text { mentas têm premiações pela continuidade de acesso ou pela quantidade de acertos alcançados durante } \\
\text { o percurso. Outras premiam com acesso a conteúdos restritos ou, ainda, enviando convites e lembretes ao } \\
\text { usuário para que volte a usar a plataforma ou o aplicativo, por exemplo. }\end{array}$ \\
\hline Afetividade & $\begin{array}{l}\text { Acreditar que as tecnologias devam ser integradas ao processo de ensino-aprendizagem implica em entender } \\
\text { como a afetividade do usuário é considerada. É preciso que o aprendiz se sinta acolhido para que tenha } \\
\text { motivação para continuar a usar a TDIC. A relação afetiva com o aluno virtual pode ser fundamental para } \\
\text { que ele dê continuidade a seus estudos online. A expressão da afetividade pode ser percebida pelo uso de } \\
\text { emojis (ideogramas utilizados em plataformas digitais para expressar a reação ou sentimento do leitor). Outras } \\
\text { formas podem ser a criação de ícones próprios da ferramenta ou mesmo uma resposta imediata que, ainda } \\
\text { que gerada pelo próprio programa e não algo personalizada para cada aprendiz pode gerar fidelização de } \\
\text { uso e sensação de satisfação com a TDIC. }\end{array}$ \\
\hline
\end{tabular}

Fonte: Sabota e Pereira (2017, p. 55).

Além dos aspectos levantados pelos autores no item afetividade, é importante também inserir nesse contexto a análise de uma linguagem conversacional, que seja próxima do aluno e com a qual ele se sinta acolhido. A linguagem é um instrumento que atua na interação entre os agentes no processo de aprendizagem e na humanização desse processo no ambiente virtual de aprendizagem. Este é, portanto, um fator imprescindível para o envolvimento e motivação do aluno (CUNHA, 2006).

\section{Metodologia}

Nesse estudo optou-se pela pesquisa qualitativa. Em relação aos objetivos, escolheuse a pesquisa descritiva. Quanto aos seus procedimentos técnicos, trata-se de um estudo de caso tendo como locus o ambiente virtual de aprendizagem do Centro Federal de Educação Tecnológica de Minas Gerais. Para conseguir o acesso ao ambiente analisado, foi necessária a autorização do coordenador geral do Núcleo de Educação a Distância da instituição. Desta forma, foi criado um usuário (com login e senha) para cada uma das pesquisadoras, para que pudessem ter acesso ao ambiente virtual de aprendizagem Moodle, que hospedam os cursos técnicos de nível médio ofertados a distância. Sobre o instrumento de coleta de dados, usouse a observação não participativa neste ambiente virtual.

Vale ressaltar que foram observados os Objetos de Aprendizagem do Moodle do curso técnico de nível médio de Meio ambiente ofertado a distância, já que este curso foi o que mais apresentou Objetos de Aprendizagem em seu AVA. Durante o desenvolvimento da pesquisa, estava em vigor o II módulo do curso (são ao todo IV módulos).

A pesquisa foi realizada em quatro etapas, desenvolvidas em 2018:

$1^{\text {a }}$ etapa: levantamento dos objetos de aprendizagem presentes no AVA do Centro Federal de Educação Tecnológica de Minas Gerais, referente ao curso técnico de Meio Ambiente. 
$2^{\text {a }}$ etapa: verificação se os Objetos de Aprendizagem levantados na $1^{\text {a }}$ etapa atendem aos aspectos teóricos de acordo com os critérios para avaliação de material didático digital dos autores Sabota e Pereira (2017).

$3^{\text {a }}$ etapa: verificação se os Objetos de Aprendizagem levantados na $1^{\text {a }}$ etapa atendem aos aspectos práticos de acordo com os critérios para avaliação de material didático digital dos autores Sabota e Pereira (2017).

$4^{\text {a }}$ etapa: verificação se os Objetos de Aprendizagem levantados, na $1^{\text {a }}$ etapa, atendem aos aspectos técnicos relacionados à avaliação do AVA de acordo com os autores Sabota e Pereira (2017).

\section{Apresentação e Análise dos Resultados}

\section{Resultados da $1^{a}$ etapa}

Dentre os Objetos de Aprendizagem presentes no ambiente virtual de aprendizagem do curso técnico de Meio ambiente ofertado a distância, foram selecionados 15 para a análise. Como parâmetro de seleção dos objetos de aprendizagem foram levados em consideração os diferentes formatos, mídias e características apresentados no AVA (Quadro 5).

Quadro 5 - Objetos de Aprendizagem presentes no AVA do Centro Federal de Educação Tecnológica de Minas Gerais, referente ao curso técnico de Meio Ambiente

\begin{tabular}{|c|c|c|c|c|}
\hline Objeto de Aprendizagem & $\begin{array}{l}\text { Disciplina do curso de } \\
\text { Meio ambiente }\end{array}$ & Formato & Tipo & $\begin{array}{l}\text { Duração / } \\
\text { Tamanho }\end{array}$ \\
\hline 1. Distribuição da água na natureza & Gestão de Efluentes & $\begin{array}{l}\text { Arquivo produzido em power- } \\
\text { point, com extensão portable } \\
\text { document format (PDF) }\end{array}$ & Apresentação & 50 telas \\
\hline $\begin{array}{l}\text { 2. Apostila da disciplina Gestão de } \\
\text { fluentes }\end{array}$ & Gestão de Efluentes & $\begin{array}{l}\text { Arquivo produzido em Word, } \\
\text { com extensão PDF }\end{array}$ & E-book & 68 páginas \\
\hline 3. Reportagem Planeta Água & Gestão de Efluentes & Vídeo & $\begin{array}{l}\text { Reportagem tele- } \\
\text { visiva }\end{array}$ & 9 minutos \\
\hline $\begin{array}{l}\text { 4. Vídeo animado: qualidade da } \\
\text { água }\end{array}$ & Gestão de Efluentes & Vídeo & Animação & 4 minutos \\
\hline $\begin{array}{l}\text { 5. Norma Técnica sobre a preven- } \\
\text { ção e técnicas de amostragem } \\
\text { de efluentes }\end{array}$ & Gestão de Efluentes & Arquivo de extensão PDF & Norma Técnica & 22 páginas \\
\hline $\begin{array}{l}\text { 6. Estudo de Caso: análise técnica } \\
\text { do processo de tratamento de } \\
\text { efluente }\end{array}$ & Gestão de Efluentes & $\begin{array}{l}\text { Arquivo produzido em word } \\
\text { com extensão PDF. }\end{array}$ & Estudo de caso & 13 páginas \\
\hline $\begin{array}{l}\text { 7. Manual de orientações básicas } \\
\text { para o tratamento de esgoto }\end{array}$ & Gestão de Efluentes & Arquivo de extensão PDF & $\begin{array}{l}\text { Manual de orien- } \\
\text { tações básicas }\end{array}$ & 27 páginas \\
\hline 8. Cartaz: higienize as mãos & Microbiologia Ambiental & $\begin{array}{l}\text { Arquivo de imagem - extensão } \\
\text { portable network graphics (PNG) }\end{array}$ & Imagem & 1 página \\
\hline $\begin{array}{l}\text { 9. Reportagem BBC News: as su- } \\
\text { perbactérias }\end{array}$ & Microbiologia Ambiental & $\begin{array}{l}\text { Página de internet - extensão } \\
\text { hyperText markup language } \\
\text { (HTML) }\end{array}$ & Reportagem & 1 página \\
\hline $\begin{array}{l}\text { 10. Infográfico: como surgem cepas } \\
\text { resistentes }\end{array}$ & Microbiologia Ambiental & $\begin{array}{l}\text { Arquivo de imagem - extensão } \\
\text { PNG }\end{array}$ & $\begin{array}{l}\text { Infográfico está- } \\
\text { tico }\end{array}$ & 1 tela \\
\hline 11. O mundo secreto dos jardins & Microbiologia Ambiental & Vídeo & Videoaula & 22 minutos \\
\hline 12. Portal São Francisco & Microbiologia Ambiental & $\begin{array}{l}\text { Página da internet - extensão } \\
\text { HTML }\end{array}$ & Portal educacional & $\begin{array}{l}\text { Acesso para } 15 \text { ca- } \\
\text { nais de disciplinas }\end{array}$ \\
\hline $\begin{array}{l}\text { 13. On ou Off: de que lado você } \\
\text { está? }\end{array}$ & Química Ambiental II & Vídeo & $\begin{array}{l}\text { Vídeo motivacio- } \\
\text { nal }\end{array}$ & 4 minutos \\
\hline 14. Charge: Radioatividade & Química Ambiental II & Arquivo de imagem - PNG & Charge & Imagem pequena \\
\hline 15. Cartilha sobre agrotóxicos & Química Ambiental II & Arquivo com extensão PDF & Cartilha & 26 páginas \\
\hline
\end{tabular}

Fonte: elaborado pelas autoras. 
Portanto, percebe-se a diversidade de formatos, mídias e de características dos 15 Objetos de Aprendizagem do curso de Meio Ambiente, apresentando assim, uma variedade de recursos utilizados. Para Silveira e Carneiro (2012), o professor deve proporcionar aos alunos maior variedade de recursos para os conteúdos apresentados, uma vez que esses materiais despertam novas ideias, induzem os alunos a relacionarem conceitos e estimulam a curiosidade e resolução de problemas.

Ainda sobre os dados do Quadro 5, observa-se que alguns objetos da disciplina Gestão de Efluentes apenas reproduzem conceitos. O Objeto de Aprendizagem número 1, por exemplo, trata-se de um material produzido para a modalidade presencial no formato powerpoint, com o conteúdo disponibilizado em formato de tópicos, que não atende às especificidades da modalidade a distância, uma vez que não possui elementos específicos da modalidade como melhor contextualização da matéria, linguagem adequada, hiperlinks, dentre outros. Por isso, pode-se dizer que este Objeto de Aprendizagem não auxilia de forma eficaz os alunos no processo de aprendizagem, uma vez que não estava contextualizado e atrelado a uma discussão crítica sobre o assunto.

\section{Resultado da $2^{a}$ etapa}

Nesta etapa foram criadas perguntas norteadoras para cada aspecto teórico, com base nos conceitos dos autores Sabota e Pereira (2017), com o propósito de facilitar a análise das características dos Objetos de Aprendizagem. As perguntas norteadoras foram as listadas a seguir.

- Concepção de ensino e aprendizagem: possui uma concepção didática, tratado como processos de desenvolvimento pessoal e intelectual?

- Avaliação: é utilizado como ferramenta de avaliação, auxiliando no desenvolvimento do aprendiz ou fornecendo algum diagnóstico do estado atual do seu saber?

- Interação e interatividade: é prevista a interação entre pessoas ou com o instrumento e seu conteúdo?

- Recursos: os elementos gráficos e os textos incentivam os usuários a correlacionar o conteúdo presente com outras fontes e mídias?

- Multimodalidade: o objeto é multimodal, ou seja, emprega duas ou mais modalidades linguísticas (linguagem verbal e não verbal), com o objetivo de proporcionar uma melhor inserção do leitor no mundo contemporâneo?

Dessa forma, segue o Quadro 6, do qual é possível verificar de forma compilada a presença ou não desses aspectos em cada Objetos de Aprendizagem levantado na $1^{\text {a }}$ etapa (Quadro 5). 
Quadro 6 - Verificação da presença dos aspectos teóricos nos Objetos de Aprendizagem

\begin{tabular}{|c|c|c|c|c|c|c|c|c|c|c|}
\hline $\begin{array}{c}\text { Objetos } \\
\text { de } \\
\text { Aprendizagem }\end{array}$ & $\begin{array}{c}\text { Possui concepção } \\
\text { de ensino e } \\
\text { aprendizagem? }\end{array}$ & \multicolumn{2}{|c|}{$\begin{array}{c}\text { Possui ferramenta } \\
\text { de avaliação? }\end{array}$} & \multicolumn{2}{c|}{$\begin{array}{c}\text { Possui interação e } \\
\text { interatividade? }\end{array}$} & \multicolumn{2}{c|}{$\begin{array}{c}\text { Possui recursos } \\
\text { correlacionados? }\end{array}$} & \multicolumn{2}{c|}{$\begin{array}{c}\text { Possui } \\
\text { multimodalidade? }\end{array}$} \\
\cline { 2 - 14 } & Sim & Não & Sim & Não & Sim & Não & Sim & Não & Sim & Não \\
\hline 1 & $\mathrm{x}$ & - & - & $\mathrm{x}$ & - & $\mathrm{x}$ & - & $\mathrm{x}$ & $\mathrm{x}$ & - \\
\hline 2 & $\mathrm{x}$ & - & - & $\mathrm{x}$ & - & $\mathrm{x}$ & $\mathrm{x}$ & - & $\mathrm{x}$ & - \\
\hline 3 & - & $\mathrm{x}$ & - & $\mathrm{x}$ & - & $\mathrm{x}$ & - & $\mathrm{x}$ & $\mathrm{x}$ & - \\
\hline 4 & $\mathrm{x}$ & - & - & $\mathrm{x}$ & - & $\mathrm{x}$ & - & $\mathrm{x}$ & $\mathrm{x}$ & - \\
\hline 5 & - & $\mathrm{x}$ & - & $\mathrm{x}$ & - & $\mathrm{x}$ & $\mathrm{x}$ & - & - & $\mathrm{x}$ \\
\hline 6 & - & $\mathrm{x}$ & - & $\mathrm{x}$ & - & $\mathrm{x}$ & - & $\mathrm{x}$ & - & $\mathrm{x}$ \\
\hline 7 & $\mathrm{x}$ & - & - & $\mathrm{x}$ & - & $\mathrm{x}$ & $\mathrm{x}$ & - & $\mathrm{x}$ & - \\
\hline 8 & - & $\mathrm{x}$ & - & $\mathrm{x}$ & - & $\mathrm{x}$ & - & $\mathrm{x}$ & $\mathrm{x}$ & - \\
\hline 9 & - & $\mathrm{x}$ & - & $\mathrm{x}$ & - & $\mathrm{x}$ & - & - & $\mathrm{x}$ & - \\
\hline 10 & $\mathrm{x}$ & - & - & $\mathrm{x}$ & - & $\mathrm{x}$ & - & $\mathrm{x}$ & $\mathrm{x}$ & - \\
\hline 11 & $\mathrm{x}$ & - & - & $\mathrm{x}$ & - & $\mathrm{x}$ & - & $\mathrm{x}$ & $\mathrm{x}$ & - \\
\hline 12 & $\mathrm{x}$ & - & $\mathrm{x}$ & - & $\mathrm{x}$ & - & $\mathrm{x}$ & $\mathrm{x}$ & $\mathrm{x}$ & - \\
\hline 13 & - & $\mathrm{x}$ & - & $\mathrm{x}$ & - & $\mathrm{x}$ & - & $\mathrm{x}$ & $\mathrm{x}$ & - \\
\hline 14 & $\mathrm{x}$ & - & - & $\mathrm{x}$ & - & $\mathrm{x}$ & - & $\mathrm{x}$ & $\mathrm{x}$ & - \\
\hline 15 & $\mathrm{x}$ & - & - & $\mathrm{x}$ & - & $\mathrm{x}$ & $\mathrm{x}$ & - & $\mathrm{x}$ & - \\
\hline
\end{tabular}

Fonte: elaborado pelas autoras.

Dentro dos aspectos teóricos diagnosticou-se que, dos 15 objetos analisados, $60 \%$ apresentavam destacadamente a concepção de ensino aprendizagem, explicitando uma proposta pedagógica, enquanto em $40 \%$ dos objetos não era apresentada esta concepção. Sabota e Pereira (2017) afirmam que esses materiais devem ser tratados como processos de desenvolvimento pessoal e intelectual, inseridos dentro de um contexto histórico e sociocultural. Deste modo, cabe ressaltar que os objetivos de aprendizagem devem estar explícitos no material, e ainda, além de um material digital, um Objetos de Aprendizagem precisa funcionar como um elemento facilitador do processo de ensino e aprendizagem.

No aspecto avaliação apurou-se que dos objetos analisados, 93,33\% não possuíam esta característica ou não eram utilizadas como instrumento avaliativo na proposta pedagógica, ou seja, apenas $6,67 \%$ representavam esta função. Os professores no ambiente virtual disponibilizavam de forma geral avaliações desvinculadas dos objetos de aprendizagem. Entre os possíveis motivos pela escolha de objetos que não apresentam a característica avaliativa, a falta de orientação pedagógica sobre as possibilidades de uso é uma hipótese. Muitas vezes, os professores ficam restritos às possibilidades de avaliação, prendendo-se apenas às ferramentas avaliativas do Moodle, como por exemplo questionário, envio de tarefa e fórum.

No que concerne ao aspecto da interação e interatividade, apenas $6,67 \%$ dos Objetos de Aprendizagem possuem algum nível presente. A maior parte dos objetos analisados, que representa uma fatia de $75 \%$, não apresentou estes aspectos. Como posto por Arrais (2013), saber conjugar a interatividade dentro de um plano pedagógico é um desafio, uma vez que o educador deve saber mediar, conjugar os níveis de interatividade e conseguir resultados concisos no envolvimento dos alunos na construção do saber. Conforme Sabota e Pereira (2017), os Objetos de Aprendizagem que apresentam esses aspectos promovem uma conexão entre a teoria e a prática, instigando os alunos a apropriarem-se dos conhecimentos que envolvem os conteúdos. 
Com relação ao aspecto recursos, observou-se que $33,35 \%$ dos Objetos de Aprendizagem correlacionam o conteúdo com outras fontes e mídias, o que representa menos da metade dos Objetos de Aprendizagem analisados, uma vez que $66,65 \%$ dos objetos não fazem essa correlação. Importante ressaltar que cada objeto deve ajudar os alunos a alcançar um objetivo previamente especificado. Ao mesmo tempo, quando se tem objetos que dialogam com outros recursos como, por exemplo, um blog que também permite a utilização de um fórum ou a realização de uma atividade, ou mesmo uma apresentação em prezi, que incorpore um conteúdo no formato de vídeo, torna-se possível atingir um maior número de alunos.

No que concerne ao aspecto de multimodalidade, ou seja, presença das múltiplas modalidades da linguagem no objeto, sejam elas verbais ou não verbais, observou-se que $86,67 \%$ dos Objetos de Aprendizagem apresentam esse aspecto. Apenas 13,33\% dos objetos não apresentaram aspectos multimodais. A presença desse aspecto provavelmente se deve ao fato de que um texto ou um objeto de aprendizagem, de forma geral, não é construído linguisticamente apenas por meio da escrita, mas também por imagens ou pela articulação e integração destas formas. A presença de hipertexto também se faz importante, pois proporciona um caráter não-linear em que o leitor pode também selecionar as informações e os caminhos de leitura que preferir.

O Objetos de Aprendizagem Reportagem BBC News (Quadro 5) é um sólido exemplo de recurso multimodal, uma vez que no corpo do texto eles apresentam diversos hiperlinks nos assuntos ou palavras que estejam relacionados. Isso permite que o próprio aluno assuma uma posição mais autônoma, escolhendo as informações e a ordem que prefere acessar (SABOTA; PEREIRA, 2017).

\section{Resultado da $3^{a}$ etapa}

Nesta etapa foram criadas perguntas norteadoras para cada aspecto prático, com base nos conceitos dos autores Sabota e Pereira (2017), com o propósito de facilitar a análise das características dos Objetos de Aprendizagem. As perguntas norteadoras foram as listadas a seguir.

- Flexibilização: o aluno pode navegar livremente pelo conteúdo/atividades e escolher a ordem de acesso, favorecendo a autonomia?

- Engajamento: possui estímulos para que o aluno continue engajado e acessando o conteúdo?

- Afetividade: possui elementos que favoreçam a afetividade, como emojis, respostas imediatas (feedbacks) e linguagem dialógica?

Dessa forma, segue o Quadro 7, a partir do qual é possível verificar de forma compilada a presença ou não desses aspectos em cada Objetos de Aprendizagem levantado na $1^{\text {a }}$ etapa (Quadro 5). 
Quadro 7 - Verificação da presença dos aspectos práticos nos Objetos de Aprendizagem

\begin{tabular}{|c|c|c|c|c|c|c|}
\hline \multirow{2}{*}{$\begin{array}{c}\text { Objetos } \\
\text { de } \\
\text { Aprendizagem }\end{array}$} & \multicolumn{2}{|c|}{ Flexibilização } & \multicolumn{2}{c|}{ Engajamento } & \multicolumn{2}{c|}{ Afetividade } \\
\cline { 2 - 7 } & Sim & Não & Sim & Não & Sim & Não \\
\hline 1 & - & $\mathrm{x}$ & - & $\mathrm{x}$ & - & $\mathrm{x}$ \\
\hline 2 & - & $\mathrm{x}$ & - & $\mathrm{x}$ & - & $\mathrm{x}$ \\
\hline 3 & - & $\mathrm{x}$ & $\mathrm{x}$ & - & $\mathrm{x}$ & - \\
\hline 4 & - & $\mathrm{x}$ & - & $\mathrm{x}$ & $\mathrm{x}$ & - \\
\hline 5 & - & $\mathrm{x}$ & - & $\mathrm{x}$ & - & $\mathrm{x}$ \\
\hline 6 & - & $\mathrm{x}$ & - & $\mathrm{x}$ & - & $\mathrm{x}$ \\
\hline 7 & - & - & - & $\mathrm{x}$ & $\mathrm{x}$ & - \\
\hline 8 & - & $\mathrm{x}$ & - & $\mathrm{x}$ & - & $\mathrm{x}$ \\
\hline 9 & $\mathrm{x}$ & - & - & $\mathrm{x}$ & - & $\mathrm{x}$ \\
\hline 10 & - & $\mathrm{x}$ & - & $\mathrm{x}$ & - & $\mathrm{x}$ \\
\hline 11 & - & $\mathrm{x}$ & - & $\mathrm{x}$ & - & $\mathrm{x}$ \\
\hline 12 & $\mathrm{x}$ & - & - & $\mathrm{x}$ & - & $\mathrm{x}$ \\
\hline 13 & - & $\mathrm{x}$ & $\mathrm{x}$ & - & $\mathrm{x}$ & - \\
\hline 14 & - & $\mathrm{x}$ & - & $\mathrm{x}$ & - & $\mathrm{x}$ \\
\hline 15 & $\mathrm{x}$ & - & - & $\mathrm{x}$ & $\mathrm{x}$ & - \\
\hline
\end{tabular}

Fonte: elaborado pelas autoras.

Analisando os dados do Quadro 7 percebe-se que, no quesito de flexibilização, apenas 20\% dos Objetos de Aprendizagem apresentam este aspecto nos cursos técnicos de nível médio a distância do Centro Federal de Educação Tecnológica de Minas Gerais. Deste modo, a maioria dos objetos analisados (80\%) não apresentam esta característica. Este resultado aponta para um prejuízo na proposta pedagógica do curso.

Sobre o quesito engajamento, dos objetos analisados 13,33\% apresentam esse aspecto nos cursos técnicos a distância de nível médio do Centro Federal de Educação Tecnológica de Minas Gerais, o que representa um número inexpressivo. Isto significa que $80 \%$ destes objetos não promovem o engajamento no processo de ensino e aprendizagem. Levando em consideração a afirmação de Sabota e Pereira (2017) que asseguram ser o engajamento um aspecto relevante nos materiais didáticos digitais, uma vez que promove, muito além do acesso, a sua continuidade de estudo e a oportunidade de desenvolvimento da consciência da aprendizagem, mais uma vez houve prejuizo na proposta pedagógica do curso.

Com relação à afetividade, $66,66 \%$ dos objetos analisados não apresentaram essa característica nos cursos, o que é uma desvantagem para o ensino, especialmente para a EaD, pois o Objetos de Aprendizagem deve ser motivador e apresentar uma aproximação com vistas a suprir a ausência física do professor. Sabota e Pereira (2017) reforçam que, além da linguagem, outras ações fazem com que os alunos se sintam acolhidos e motivados a continuar utilizando o material, como por exemplo, a presença de emojis, avatares ou respostas imediatas e afetivas geradas pelo próprio programa.

\section{Resultado da $4^{a}$ etapa}

Nesta etapa foram verificados os aspectos técnicos relacionados ao AVA usado pelo curso técnico de Meio ambiente, embasados nos conceitos dos autores Sabota e Pereira (2017) com o propósito de melhor contextualizar, uma vez que é no ambiente virtual de aprendizagem Moodle que todo o processo acontece (Quadro 8). 
Quadro 8 - Aspectos técnicos relacionados à avaliação do AVA Moodle do Centro Federal de Educação Tecnológica de Minas Gerais

\begin{tabular}{|c|c|}
\hline $\begin{array}{l}\text { Aspectos } \\
\text { técnicos }\end{array}$ & Detalhamento \\
\hline $\begin{array}{l}\text { Design / } \\
\text { Layout }\end{array}$ & $\begin{array}{l}\text { - O ambiente Moodle é um ambiente amigável, contudo sua forma de personalização pode impactar o aluno, positiva } \\
\text { ou negativamente. Porém, os elementos apresentados no layout do Moodle analisado são dispostos de forma pouco } \\
\text { atraente. As páginas iniciais das disciplinas possuem informações dispostas, separadas por unidades. As disciplinas } \\
\text { Gestão de efluentes, microbiologia ambiental e química ambiental } 2 \text { apresentam imagens - fotografias, infográficos, } \\
\text { mapas conceituais, charges - em cada unidade, contextualizando com o tema proposto, contudo em tamanhos } \\
\text { despadronizados; } \\
\text { - As tipografias apresentadas nas páginas das diversas disciplinas possuem diferentes tipos de fonte de letra e diferentes } \\
\text { tamanhos, o que gera dificuldade na leitura e uma percepção confusa e poluída. Falta também uma padronização } \\
\text { para textos e títulos; } \\
\text { - Oestilo visual com fontes, cores, imagens, que são partes funcionais do design, de forma geral, nas páginas das disciplinas } \\
\text { analisadas, não formam uma composição harmônica e agradável, dificultando a interação da interface com o aluno. }\end{array}$ \\
\hline Acessibilidade & $\begin{array}{l}\text { - O acesso ao Moodle é fácil e intuitivo, da mesma forma com relação aos comandos dentro das páginas das disciplinas. } \\
\text { Para ter acesso ao conteúdo, o aluno após efetuar o seu login e clicar no curso, em seguida no módulo desejado e } \\
\text { posteriormente na disciplina correspondente; } \\
\text { - O ambiente das disciplinas possui uma navegação com uma ordem estabelecida por seções: apresentação, unidades e } \\
\text { avaliaçães. Contudo, dentro de cada seção, não existe uma ordem de documentos padronizados disponibilizados aos } \\
\text { alunos, por exemplo: plano de ensino, carta de boas-vindas, cronograma, mini currículo do professor, fórum de avisos; } \\
\text { - Na disciplina de microbiologia ambiental, por exemplo, a apostila completa do conteúdo já foi disponibilizada in- } \\
\text { tegralmente na seção de apresentação, enquanto nas outras disciplinas elas foram disponibilizadas em arquivo pdf } \\
\text { dividida conforme a unidade proposta; } \\
\text { - Outro ponto a se destacar com relação à navegação nas páginas das disciplinas são os menus confusos e despadroni- } \\
\text { zados. A navegação se faz importante na medida em que encurta o caminho do aluno, simplificando e encurtando o } \\
\text { seu objetivo e tornando a experiência de navegação mais envolvente. Manter o aluno no ambiente em uma posição } \\
\text { da qual ele não sabe onde está, por meio de uma navegação complexa pode gerar evasão na disciplina, uma vez que } \\
\text { o aluno pode vir a abandonar a página do curso; } \\
\text { - Cabe dizer que este Moodle pode ser acessado por meio de outros dispositivos, permitindo a integração de mídias } \\
\text { e facilitando a interação do usuário com o conteúdo. }\end{array}$ \\
\hline Suporte & $\begin{array}{l}\text { - O suporte técnico no AVA das disciplinas é feito pelos tutores a distância ou pelos tutores presenciais. Caso não saibam } \\
\text { resolver algum problema técnico solicitado pelo aluno, a dúvida é encaminhada ao coordenador de Tecnologia da } \\
\text { Informação (TI) do Centro Federal de Educação Tecnológica de Minas Gerais; } \\
\text { - Para enviar mensagem ao tutor no ambiente virtual, é necessário que o aluno clique na opção Participantes, e escolha } \\
\text { o nome do tutor; } \\
\text { - Não foram verificados aspectos essenciais ao ambiente virtual, conforme os autores Sabota e Pereira (2017) estipu- } \\
\text { lam, como: seções de perguntas mais frequentes (FAQ); tutoriais disponibilizados para auxiliar o entendimento de } \\
\text { ferramentas menos conhecidas; acessibilidade para pessoas com limitações/necessidades especiais; } \\
\text { - Percebeu-se, contudo, nas três disciplinas (gestão de efluentes / microbiologia ambiental / química ambiental 2) o } \\
\text { cuidado na linguagem utilizada com os alunos por meios dos vídeos e fóruns, buscando a dialogicidade e o esclare- } \\
\text { cimento de termos técnicos relativos ao conteúdo; } \\
\text { - Deste modo, é disponibilizado ao aluno meios de contato como mensagem pelo próprio AVA, chat e fórum de dúvidas, } \\
\text { respondido em até } 48 \text { horas. }\end{array}$ \\
\hline
\end{tabular}

Fonte: elaborado pelas autoras.

Desta forma, a análise do AVA do Centro Federal de Educação Tecnológica de Minas Gerais permitiu verificar que, apesar de contemplar os aspectos técnicos ora postulados por Sabota e Pereira (2017) para avaliação de um ambiente virtual de aprendizagem, o Moodle ainda apresenta acepções que necessitam de melhorias na sua dimensão pedagógica e técnica.

\section{Análise final}

Em síntese, as análises realizadas ao longo das etapas desta pesquisa permitiram inferir algumas considerações, tais como: não existe uma padronização acerca dos materiais base de estudo disponibilizados para o aluno no AVA. Os conteúdos em powerpoint apresentam características de apresentações presenciais, o que não auxilia na efetiva aprendizagem do aluno. As apostilas das disciplinas, por exemplo, são formatadas de maneiras distintas: algumas mais didáticas apresentam ícones como reflexão, saiba mais, curiosidade e imagens 
que auxiliam o entendimento sobre o assunto. A maioria, porém, não apresenta estas características. Por serem conteúdos que demandam características específicas da modalidade a distância, seria importante implantar no processo de produção destes materiais base a padronização da linguagem e dos elementos didáticos envolvidos, trabalho este desenvolvido usualmente pelo pedagogo ou designer instrucional. Estes materiais base são, portanto, ofertados e disponibilizados juntamente com os Objetos de Aprendizagem previamente selecionados pelos professores ou equipe.

Também não existe uma padronização com relação à forma que os objetos de aprendizagem são disponibilizados aos alunos no ambiente virtual de aprendizagem. Havia disciplinas nas quais a acessibilidade demandaria um caminho demasiadamente longo no ambiente para acesso do objetos de aprendizagem; vídeos sem títulos fazendo com que o próprio aluno tivesse que abrir um a um para verificar do que tratava o conteúdo. Em algumas disciplinas, os objetos de aprendizagem eram separados por módulos, de acordo com o assunto. Em outras, era disponibilizado apenas uma lista com estes materiais para acesso, o que dificulta para o aluno compreender quais fazem parte de determinado assunto. Além disso, percebeu-se a ausência de tutoriais que facilitam o uso dos objetos de aprendizagem juntamente com os objetivos de aprendizagem pré-estabelecidos.

Outra conclusão é que os objetos de aprendizagem, em sua maioria, não estavam descritos previamente, como, por exemplo, uma sinopse do que seria apresentado. Com isso, o aluno fica impossibilitado de compreender previamente o que ele irá aprender acessando o conteúdo. A sensação ao navegar pelo layout no AVA é que em algumas disciplinas, muitos objetos de aprendizagem estavam soltos e descontextualizados, ou seja, presentes apenas para inserção em termos quantitativos no AVA e, em alguns destes materiais analisados faltou uma orientação prévia com relação a sua utilização técnica. Além disso, ao utilizar um OA pertencente a outras instituições, é necessário solicitar autorização de uso por envolver questões de direitos autorais. Verificou-se que não existe um critério com relação a isso e que os professores não possuem este direcionamento.

Enfim, a análise descritiva realizada nesta pesquisa referente a cada um dos Objetos de Aprendizagem auxilia como parâmetro e diretriz para que os professores de diversos níveis de ensino e diferentes modalidades, seja a distância ou como forma de suporte no presencial, utilizem no momento da escolha estratégias de análise para mídias e demais materiais didáticos digitais, com o intuito de produzirem cursos com propostas assertivas e atender as necessidades reais dos alunos, proporcionando uma aprendizagem significativa.

\section{Considerações Finais}

Atualmente, existem alguns repositórios de Objetos de Aprendizagem que o professor pode utilizar em instituições públicas ou privadas, sendo estes de caráter gratuito, sem a necessidade de autorização ou compra do conteúdo. Usualmente, estes Objetos de Aprendizagem são categorizados e ofertados por disciplina ou tema. Cabe dizer que o professor pode fazer uso de vários Objetos de Aprendizagem para tratar de um mesmo assunto, desde que imprima sentido, mesclando diversos aspectos de cada um deles.

Dentro deste contexto de escolha e utilização de Objetos de Aprendizagem, conforme propõe Sabota e Pereira (2017), é de suma importância que se observem, em um primeiro momento, as características individuais dos alunos, seus conhecimentos prévios, a forma 
que eles aprendem melhor, a familiaridade com as tecnologias digitais, dentre outros aspectos, tendo em vista que a escolha dos materiais adequados envolvem esses pressupostos e interferem na avaliação de um Objeto de Aprendizagem. Além disso, é importante ressaltar que como cada turma possui suas especificidades, é necessário que o professor conheça o perfil dos seus alunos para escolher adequadamente os tipos de materiais que irá utilizar, embora a realidade que muitos professores encontram pela frente são de turmas lotadas, tanto na EaD quanto no presencial, o que dificulta este papel (ANTUNES, 2001). Ainda assim, reforça-se a importância de localizar meios e estratégias para esta aproximação, visto que esta ação impacta diretamente na satisfação do uso dos Objetos de Aprendizagem por parte dos alunos.

Portanto, o instrumento de análise proposto por Sabota e Pereira (2017) que serviu de base para este estudo é uma possibilidade, dentre várias outras, que pode ser utilizada na seleção e análise dos Objetos de Aprendizagem e demais materiais didáticos destinados ao processo de ensino e aprendizagem. Assim, ao final da pesquisa, foi possível concluir que muitos dos recursos disponíveis no AVA do curso analisado não contemplam aspectos como interação e interatividade, engajamento, afetividade e flexibilização, aspectos esses necessários para o estabelecimento de uma boa prática pedagógica para a atuação na modalidade. Salienta-se, ainda, que a falta de orientação pedagógica quanto à escolha e utilização desses Objetos de Aprendizagem, impossibilita o professor de atuar de forma condizente com as especificidades da EaD e do Ensino Técnico, que por sua vez envolvem a utilização de teoria articulada a um conhecimento didático-pedagógico e que ainda possibilita ao aluno uma formação na sua totalidade. Por fim, demonstrou-se como os Objetos de Aprendizagem podem ser selecionados e analisados por professores ou pela equipe educacional envolvida no processo de ensino e aprendizagem.

\section{Referências}

ANTUNES, C. As inteligências múltiplas e seus estímulos. 7. ed. Campinas: Papirus, 2001.

ARRAIS, M. Contribuições de um objeto de aprendizagem para uma interface gráfica imersiva e interativa no AVA moodle. 2013. 112 f. Dissertação (Mestrado em Educação tecnológica) - Centro Federal de Educação Tecnológica de Minas Gerais, Belo Horizonte, 2013.

BELLONI, M. L. Educação a distância. 7. ed. Campinas: Autores Associados, 2015.

BISOL, C. A. Ciberespaço: terceiro elemento na relação ensinante/aprendente. In:

VALENTINI, C. B.; SOARES, E. M. S. (org.). Aprendizagem em ambientes virtuais: compartilhando ideias e construindo cenários. 2. ed. Caxias do Sul: Educs, 2010. p. 21-32.

CUNHA, A. L. A interação na educação a distância: cuidados com o uso da linguagem em cursos online. In: SEMINÁRIO NACIONAL DE EDUCAÇÃO A DISTÂNCIA, 4., 2006, Brasília. Anais [...]. Brasília: ABED, 2006. p. 1-9. Disponível em: http://www.abed.org.br/seminario2006/pdf/tc011.pdf. Acesso em: 15 out. 2017.

DELGADO, L. M. M. Uso da plataforma moodle como apoio ao ensino presencial: um estudo de caso. 2009. 134 f. Dissertação (Mestrado em Linguística Aplicada) - Faculdade de Letras, Universidade Federal do Rio de Janeiro, Rio de Janeiro, 2009. 
GROSSI, M. G. R.; ELIAS, M. C. A. S.; CHAMON, C. M.; LEAL, D. C. C. C. The educational potentialities of the virtual learning environments moodle and canvas: a comparative study. International Journal of Information and Education Technology, Bingley, v. 8, n. 7, p. 514-519, 2018. DOI: http://doi.org/d3r9.

HODGINS, H. W. The future of learning objects. In: WILEY, D. A. (ed.). The instructional use of learning objects: online version. 2000. Disponível em: https://www.reusability.org/read/. Acesso em: 15 out. 2017.

INSTITUTE OF ELECTRICAL AND ELECTRONICS ENGINEERS. Draft standard for learning object metadata. Piscataway: IEEE, 2002.

KENSKI, V. M. Tecnologias e tempo docente. Campinas: Papirus, 2013.

MAIA, C.; MATTAR, J. ABC da EaD. São Paulo: Pearson Prentice Hall, 2007.

MAIA, C.; GARCIA, M. O trajeto da Universidade Anhembi Morumbi no desenvolvimento de ambientes virtuais de aprendizagem. In: MAIA, C. EAD.br: educação à distância no Brasil na era da internet. São Paulo: Anhembi Morumbi, 2011. p. 15-38.

MOORE, M. G.; KEARSLEY, G. Educação a distância: sistemas de aprendizagem online. São Paulo: Cengage Learning, 2008.

NIKOLOPOULOS, G.; SOLOMOU, G.; PIERRAKEAS, C.; KAMEAS, A. A modeling the characteristics of a learning object for use within e-learning applications. In: BALKAN CONFERENCE IN INFORMATICS, 5., 2012, New York. Proceedings [...]. New York: Association for Computing Machinery, 2012. p. 112-117.

LIVEIRA, E. G. Educação a distância na transição paradigmática. Campinas: Papirus, 2012.

SABOTA, B.; PEREIRA, A. L. O uso de ferramentas tecnológicas em ambientes de aprendizagem: critérios para avaliação de materiais de ensino em formato digital. Revista Caminhos em Linguística Aplicada, Taubaté, v. 16, n. 2, p. 44-62, 2017. Disponível em: https://tinyurl.com/ybwpxgvt. Acesso em: 13 jul. 2020.

SILVEIRA, M. S; CARNEIRO, M. L. F. Diretrizes para a avaliação da usabilidade de objetos de aprendizagem. In: SIMPÓSIO BRASILEIRO DE INFORMÁTICA NA EDUCAÇÃO, 23., 2012, Rio de Janeiro, 2012. Anais [...]. Rio de Janeiro: Sociedade Brasileira de Computação, 2012. Disponível em: https:// tinyurl.com/ybwww3t5. Acesso em: 13 jul. 2020.

WILEY, D. A. Connecting learning objects to instructional design theory: a definition, a metaphor, and a taxonomy. Logan: Utah State University, 2000. 